\title{
Microstructure and Creep Behaviour of as-cast Ti-48Al-4Cr
}

\author{
Esah Hamzah (Corresponding author) \& Maiiyeaalagan Kanniah \\ Department of Materials Engineering, Faculty of Mechanical Engineering \\ Universiti Teknologi Malaysia \\ 81310 Skudai, Johor, Malaysia \\ Tel: 6-07-553-4563; fax: 6-07-556-6159 E-mail: esah@fkm.utm.my
}

\author{
Mohd Harun \\ Industrial Technology Division \\ Malaysian Institute for Nuclear Technology Research \\ Bangi, 43000 Kajang, Selangor, Malaysia
}

The research is financed by Malaysian Ministry of Science, Technology and Innovation (MOSTI) under the IRPA program (Project No. 09-02-06-0002 EA-002). (Sponsoring information)

\begin{abstract}
The microstructure and creep behaviour of as-cast beta phase contained gamma titanium aluminide with nominal composition of Ti-48Al-4Cr (at.\%) was investigated. Constant load tensile creep test were performed at temperatures between $600-800^{\circ} \mathrm{C}$ and initial stresses from $150-180 \mathrm{MPa}$. Data indicates that the alloy exhibit both steady state and minimum creep behaviour depending upon the temperature and stress. Microstructure before and after creep deformation were examined using scanning electron microscopy techniques. The possible reason for the transition from steady state to minimum creep behaviour was suggested.
\end{abstract}

Keywords: Microstructure, Creep, TiAl

\section{Introduction}

TiAl based alloys are considered as promising structural materials for high temperature aerospace and automotive applications. This is essentially due to some attractive properties such as low density $(\rho \sim 3.8 \mathrm{~g} / \mathrm{cm} 3)$, high specific strength $\sigma / \rho$, high specific stiffness $E / \rho$, high temperature strength retention and resistance against 'titanium fire'. Single phase TiAl suffers from both poor room temperature ductility and fracture toughness. Therefore, no effort has been made to develop structural materials on the basis of single phase TiAl. In contrast, considerable improved ductility and toughness can be achieved in two phase alloys. Thus, during recent years extensive research has been carried out to develop two phase base alloys consisting of $\gamma$-TiAl and $\alpha_{2}-\mathrm{Ti}_{3} \mathrm{Al}$ for structural applications. The most promising alloys are based on Ti-48at.\% Al compositions with ternary or quaternary additions. The properties of these alloys are quite sensitive to microstructure; duplex structures show higher tensile ductility, for example up to $2.2 \%$ in binary Ti-48Al and up to $4 \%$ in ternary or quaternary alloys, whereas fully lamellae structures have poor ductility but higher creep resistance.

Although extensive research had been directed to improve the creep resistance (which is the primary importance for high temperature application) of two phase TiAl, however, still the design creep limit could not be meet. The presence of third phase, $\beta$, had been avoided from the beginning due to its brittleness at room temperature. Presence of $\beta$ phase is thought to worsen the poor room temperature ductility. Therefore, $\beta$ phase contained TiAl had never been studied extensively. Despite all the assumptions, $\beta$ phase contained alloys had been reported to improve room temperature ductility and high temperature formability. The role of $\beta$ phase at room and high temperature is still subject to controversy. Although, $\beta$ phase had been avoided due to deterioration of room temperature ductility, however, currently it is subject of interest.

The aim of the present work is to study the microstructure and creep behaviour of $\beta$ phase contained TiAl, namely Ti-48at.\%Al-4at.\%Cr. 


\section{Experimental procedures}

The material investigated in this study have the nominal composition of Ti-48at.\%Al-4at.\%Cr. The alloys were produced by plasma melting casting in the form of $2 \mathrm{~kg}$ buttons. The alloy will be referred in atomic percentage hereafter.

Samples before and after creep tests were examined using Phillips XL40 scanning electron microscope and Zeiss Supra 35VP field emission scanning electron microscope in back scattered electron (BSE) mode.

Flat samples with dimension, $3 \mathrm{~mm} \times 2 \mathrm{~mm}$ with $15 \mathrm{~mm}$ gauge length were prepared for the creep test. Prior to creep test, the test pieces were ground along the gauge length in the longitudinal direction to prevent premature crack initiation at surface defects during creep.

The constant load tensile creep test was conducted using Mayes TC 20 High Temperature Creep Testing Machine, consisting three zone temperature furnace and a loading lever arm ratio of 10:1 in air. The test temperatures were maintained constant with a precision of $\pm 1^{0} \mathrm{C}$ and monitored for 2 hours before the test. The temperature was monitored during the creep test by using a thermocouple in contact with the gauge section of the sample. The sample was allowed to soak at test temperature for 1 hour before the load was applied. The strain was measured using a HTD type extensometer which is attached with two linear voltage displacement transducers (LVDT) with resolution of $\pm 1 \mu \mathrm{m}$ and a data logger. The strain was measured for every 1 second intervals at the start of the creep test, increasing to a maximum interval of 15 minutes. The test was interrupted after 20 hours and the samples were left to cool in air to room temperature.

\section{Experimental Results}

\subsection{Microstructural Characterisation}

The as-cast microstructure prior to creep testing was examined carefully and quantitatively in order objectively to distinguish later any creep induced microstructural changes. Figure 1(a) and (b) shows the optical and SEM-BSE micrograph of typical nearly lamellae microstructure in the gauge region of creep samples of as-cast Ti-48Al-4Cr. The microstructure of Ti-48Al-4Cr consists three phase which are the lamellae $(300-600 \mu \mathrm{m})$, fine gamma $(5-10 \%)$ and beta $(2-5 \%)$ phase. The beta grains are observed to be irregular in shape together with fine $\gamma$ grains along grain boundaries. Therefore, it is very hard to distinguish between $\gamma$ and $\beta$ grains of Ti-48Al-4Cr at low magnifications. Although indiscernible from optical micrograph, SEM image in figure 1(b) clearly reveals the presence of $\beta$ phase (bright contrast) along lamellae grain boundaries. EDX analysis is conducted to further verify the fine $\gamma$ and $\beta$ phase. EDX analysis showed spot A have less chromium content whereas spot B are enriched with chromium. This result verifies that spot $\mathrm{A}$ is fine $\gamma$ (dark contrast) whereas spot B (bright contrast) is beta phase. This verification is based on the fact that chromium is a strong $\beta$ stabilizer. This type microstructure appears to be commonly observed in $\beta$ containing TiAl alloy, e.g. Ti-46Al-(1.5-2)Cr-2Mo-0.25Si-0.3B, Ti-46.5Al-2Cr-2Nb-0.8Mo-0.2W-0.2Si and Ti-45-10Nb. The x-ray diffraction pattern is shown in figure 1(c). In the as-cast condition, peaks due to $\alpha_{2}$ and $\gamma$ are evident. Additionally, diffraction peaks due to b.c.c. structure were identified. The $\mathrm{x}$-ray data indicate that the irregularly shaped particles enriched in $\mathrm{Cr}$ visible in figures 1(a) and 1(b) are the $\beta$ phase.

\subsection{Creep Behaviour}

Figure 2(a) and (b) illustrates the creep strain (\%) versus time (hrs) and strain rate $\left(\mathrm{hr}^{-1}\right)$ versus time (hours) for creep tests at temperatures ranging between $600-700^{\circ} \mathrm{C}$ and identical initial stress of $180 \mathrm{MPa}$ respectively. Analysis on the creep curves of figure 2(a) shows Ti-48Al-4Cr exhibit no instantaneous creep strain at 600 and $700^{\circ} \mathrm{C}$ with initial stress of 180MPa. Both these creep curves has almost identical shape. Figure 2(b) shows that Ti-48Al-4Cr exhibits steady state bahaviour at these temperature-stress regimes. The creep strain increases rapidly in the primary creep regime until strain rate gradually falls to a steady-state value. No minimum creep behaviour is observed over these temperature-stress regimes. The steady state creep rate at 600 and $700^{\circ} \mathrm{C}$ were $8.49 \times 10^{-6}$ and $1.42 \times 10^{-5} \mathrm{~s}^{-1}$ respectively. Creep testing is also attempted at $800^{\circ} \mathrm{C}$ with initial stress of $180 \mathrm{MPa}$. However, the sample failed upon loading. It is quite interesting to note that $\mathrm{Ti}-48 \mathrm{Al}-4 \mathrm{Cr}$ which exhibit quite low creep strains and steady state creep rate at temperatures between $600-700^{\circ} \mathrm{C}$ failed upon loading at $800^{\circ} \mathrm{C}$ with the same initial stress of $180 \mathrm{MPa}$. Therefore a creep test is attempted with initial stress of $150 \mathrm{MPa}$ to study the behaviour of Ti- $48 \mathrm{Al}-4 \mathrm{Cr}$ at $800^{\circ} \mathrm{C}$ and possible cause for the sudden failure with initial stress of 180MPa.

Figure 3(a) and (b) illustrates the creep strain (\%) versus time (hrs) and strain rate (hr ${ }^{-1}$ ) versus time (hours) for creep tests at $800^{\circ} \mathrm{C}$ and initial stress of $150 \mathrm{MPa}$ respectively. Ti-48Al-4Cr exhibit $0.32 \%$ of instantaneous creep strain and immediately undergoes a short primary creep and reaches a minimum value before the onset of tertiary creep. Ti-48Al-4Cr exhibits minimum creep behaviour at this condition of temperature and stress as shown in figure 3(b). This type of creep behavior is also referred as 'inverse creep' where the creep curve can be divided into two regimes, before and after the minimum creep rate, instead of the common three. The minimum creep rate is $8.5 \times 10^{-5} \mathrm{~s}^{-1}$. The sample 
failed after 16.5 hours. From this result, it is evident that the transition between steady state to minimum creep behaviour occurs at temperature between 700 to $800^{\circ} \mathrm{C}$.

\subsection{Creep Deformed Microstructure}

SEM-BSE microstructures of crept samples are shown in figure 4(a)-(c). SEM examination indicates that the $\beta$ phase at the grain boundaries decreased. On the other hand, extensive amount of $\beta$ phase was observed at the $\alpha_{2} / \gamma$ lamellae interfaces. This was contrast to the initial as-cast microstructure. It is reported that $\beta$ phase is softer than the other two phases $\left(\alpha_{2}\right.$ and $\left.\gamma\right)$ at elevated temperatures because of its more open bcc structure. That is, $\beta$ phase can be deformed more easily than $\alpha_{2}$ and $\gamma$ phases. Therefore, upon deformation, the $\beta$ phase is expected to act like a lubricant layer, and therefore, reduces the creep resistance of the alloy. Dynamic recrystallization which often been associated with high temperature deformation of TiAl is not significant in the case of $\beta$ phase contained TiAl. $\beta$ phase is found to play major role during creep deformation.

\subsection{Creep Fracture}

The fracture surface of Ti-48Al-4Cr sample creep deformed to fracture $(\varepsilon=7.98 \%)$ at $800^{\circ} \mathrm{C}$ with initial stress of $150 \mathrm{MPa}$ is shown in figure 5. A 'dimple like' appearance is observed. However, the intergranular brittle character of creep fracture is still evident. The 'dimples' are likely to be result of cavity nucleation whereas the intergranular brittle fracture had been suggested due to the $\beta$ phase at grain boundary which is to be origin for crack nucleation. These cracks propagate rapidly during final stage of creep and thus lead to the observed failure along grain boundaries.

\section{Discussion}

Ti-48Al-4Cr exhibits nearly lamellae microstructure consisting lamellae, fine $\gamma$ and $\beta$ phase. Addition of $\mathrm{Cr}$ up to 4 at.\%, introduces $\beta$ phase (bcc structure). The lamellae structure consists of alternating laths of the $\gamma$-TiAl and $\alpha_{2}-\mathrm{Ti}_{3} \mathrm{Al}$ phases. Such lamellae structure results from the solid state phase transformation of the primary disordered $\alpha$ dendrites. The single fine $\gamma$ regions surrounding the lamellae grains result from the transformation of the aluminum rich interdendritic melt due to incompleteness of the peritectic reactions. The two peritectic reactions, $L+\beta \longrightarrow \alpha$ and $L+\alpha \longrightarrow \gamma$, is hardly to be completed due to limited diffusion caused by the formation of a solid envelope of the peritectic phase, avoiding the physical contact between the reactants. As far $\beta$ phase is concerned, even though it is found to exist together with $\alpha\left(\alpha_{2}\right)$ and $\gamma$ phases in $\beta$ stabilizer added TiAl, attention has been paid mainly to the role of $\beta$ phase in the mechanical properties but not to the formation mechanism of the microstructure as well as the phase equilibria among $\beta$, $\alpha$ and $\gamma$ phases. Therefore, the microstructural formation in the alloys under development or study has in most case been interpreted based on the binary phase diagram, since the amount of the additive elements is not large. However, little attempt has been made to establish the phase relationship among the $\beta, \alpha$ and $\gamma$ at elevated temperatures.

Although countless research had associate titanium aluminide with minimum creep behaviour, however long term creep test at low stresses had shown that titanium aluminide exhibits steady state creep behaviour. In this investigation, beta phase contained TiAl, as-cast Ti-48Al-4Cr exhibited steady state creep behaviour at temperatures from $600-700^{\circ} \mathrm{C}$ with initial stress of $180 \mathrm{MPa}$, minimum creep behaviour at $800^{\circ} \mathrm{C}$ with initial stress of $150 \mathrm{MPa}$ and failed upon loading at $800^{\circ} \mathrm{C}$ with initial stress of $180 \mathrm{MPa}$. From this result it is evident that the transition from steady state to minimum creep behaviour occurs between 700 to $800^{\circ} \mathrm{C}$. This transition which causes limited secondary stage and quick onset of tertiary creep stage is due to the microstructural instabilities. Although the creep deformed SEM-BSE microstructures of as-cast $\mathrm{Ti}-48 \mathrm{Al}-4 \mathrm{Cr}$ is similar in all the three condition of temperature-stress investigated in this study where extensive amount of $\beta$ phase was present on the $\alpha_{2} / \gamma$ lamellae interfaces in contrast with the initial microstructure, there is particular microstructural instability which responsible for the quick onset of tertiary stage at $800^{\circ} \mathrm{C}$. The open bcc structure of $\beta$ phase becomes more significant at temperatures between $700-800^{\circ} \mathrm{C}$ and responsible for the quick onset of tertiary creep regime. It is well established that $\beta$ phase limits the ductility of TiAl at room temperature due to its brittleness. However, at high temperature its open bcc structure causes it to be very ductile. It is evident from the large creep stain (7.98\%) exhibited before rupture (figure 3(a)) and dimple like fractured surface after creep-rupture test at $800^{\circ} \mathrm{C}$ as shown in figure 5 . Therefore, $\beta$ phase is detrimental at both room and high temperature due to its extreme effect on ductility. However, this study shows that $\beta$ phase might be useful at intermediate temperatures. This is due to the excellent creep resistance of Ti-48Al-4Cr at temperatures from $600-700^{\circ} \mathrm{C}$. The effect of $\beta$ phase on ductility is believed to be moderate at the intermediate temperatures. The transition from steady state to minimum creep behaviour is most probably occurs when the open bcc of $\beta$ phase is significant at temperature between $700-800^{\circ} \mathrm{C}$.

The majority studies had addressed the creep behaviour of gamma TiAl based on the phenomenological description of pure metal creep. Despite the fact that creep curves of TiAl have a general shape that is similar to pure metals, the limited nature of secondary creep and increased importance of tertiary or 'inverse' creep suggest that the traditional method for describing pure metal creep is not valid for TiAl. In the absence of a pure metal description of power-law creep, an alternative method for modeling the creep behaviour of gamma TiAl is needed. Fitting the mechanical data to the existing creep mechanisms without detail understanding on the behaviour of the material as a function of 
microstructural variation or creep regime would not be appropriate. A detailed TEM study is necessary for understanding the real creep mechanisms.

\section{Conclusions}

1. As-cast Ti-48Al-4Cr exhibits nearly lamellae microstructure with coarse lamellae grains $(300-600 \mu \mathrm{m})$ and fine $\gamma$ and $\beta$ grains at the lamellae grain boundaries. The $\beta$ phase has body centered cubic crystal structure.

2. As-cast Ti-48Al-4Cr exhibit steady state creep behaviour at $600-700^{\circ} \mathrm{C}$ with initial stress of $180 \mathrm{MPa}$ and minimum creep behaviour at $800^{\circ} \mathrm{C}$ with initial stress of $150 \mathrm{MPa}$. It failed upon loading at during creep test $800^{\circ} \mathrm{C}$ and initial stress of $180 \mathrm{MPa}$.

3. Extensive formation of $\beta$ phase is observed at the $\alpha_{2} / \gamma$ lamellae interfaces whereas the initial $\beta$ phase at grain boundaries decreased after creep deformation at all the temperature-stress conditions investigated.

4. A dimple like fracture surface is observed after creep rupture test at $800^{\circ} \mathrm{C}$ and initial stress of $150 \mathrm{MPa}$.

5. The transition from steady state to minimum creep behaviour occurs at temperature between $700-800^{\circ} \mathrm{C}$. The transition is suggested due to the significant open bcc structure of $\beta$ phase at high temperature.

6. Although presence of $\beta$ phase is found to be detrimental for high temperature creep resistance, it has significant good effect for the intermediate temperature creep resistance.

\section{References}

Appel, F. \& Wagner, R. (1998). Microstructure and Deformation of Two-Phase $\gamma$-Titanium Aluminides. Materials Science and Engineering, R22, 187-268.

Chen, W.R., Triantafillou, J., Beddoes, J. \& Zhao, L. (1999). Effect of Fully Lamellar Morphology on Creep of a Near $\gamma$-TiAl Intermetallics. Intermetallics, 7, 171-178.

Clemens H \& Kestler H. (2000). Processing and Applications of Intermetallic $\gamma$-TiAl-Based Alloys. Advance Engineering Materials, 2, 551-570.

Dlouhy, A. \& Kucharova, K. (2004). Creep and Microstructure of Near-Gama TiAl Alloys. Intermetallics, 12, 705-711.

Duarte, A., Viana, F., Henrique, M. \& Santos, C.M. (1999). As-Cast Titanium Aluminides Microstructure Modification. Materials Research, 2, 1-5.

Jewett, T.J., Ahrens, B. \& Dahms, M. (1997). Stability of TiAl in the Ti-Al-Cr System. Materials Science and Engineering Part A, A225, 29-37.

Kawabata T, Fukai H \& Izumi O. (1998). Effect of ternary additions on mechanical properties of TiAl. Acta Materillia, 46(6), 2185-2194.

Kim, H.Y. \& Hong, S.H. (2002). The Effect of Microstructures on Creep Behavior of Ti-48Al-2W Intermetallic Compounds. Materials Science and Engineering Part A, A329-331, 788-794.

Kim, Y.W. \& Dimiduk, D.M. (1991). Progress in Understanding of Gamma Titanium Aluminides. Journal of the Minerals, Metal and Materials Society, 43 (8), 40-47.

Lipsitt, H.A., Blackburn, M.J., \& Dimiduk, D.M (2002). High-Temperature Structural Applications. In Westbrook, J.H. \& Fleischer, R.L. (Eds). Intermetallic Compounds: Volume 3, Principles and Practice (pp. 472-499). United Kingdom: John Wiley and Sons Ltd.

Schillinger, W., Clemens, H., Dehm, G. \& Bartels, A. (2002). Microstructural Stability and Creep Behavior of a Lamellar $\gamma$-TiAl Based Alloy with Extremely Fine Lamellae Spacing. Intermetallics, 10, 459-466.

Shao, G. \& Tsakiropoulos, P. (1999). Solidification Structures of Ti-Al-Cr Alloys. Intermetallics. 7, 579-587.

Shi JD, Pu ZJ, Zhong ZY \& Zou DX. (1992). High Temperature Deformation Behaviour of Beta-Gamma TiAl Alloy. Scripta Materillia, 27, 1331-1336.

Sun, F.S., Cao, C.X., Kim, S.E., Lee, Y.T. \& Yan, M.G. (2001). Alloying Mechanism of Beta Stabilizers in a TiAl Alloy. Metallurgical and Materials Transactions A, 32A, 1573-1589.

Takeyama, M., Ohmura, Y., Makoto Kikuchi \& Matsuo, T. (1998). Phase Equilibria and Microstructural Control of Gamma TiAl Based Alloys. Intermetallics, 6, 643-646.

Viswanathan, G.B., Kartikeyan, S., Mills, M.J. \& Vasudevan, V.K. (2001). Creep Properties of a Fully Lamellar Ti-48Al-2Cr-2Nb Alloy. Materials Science and Engineering Part A, A319-321, 833-837.

Wang, J.G. \& Nieh, T.G. (2002). Creep of a Beta Phase-Containing TiAl Alloy. Intermetallics, 8, 737-748. 
Zhang, D., Arzt, E. \& Clemens, H. (1999). Characterization of Controlled Microstructures in a $\gamma$-TiAl (Cr, Mo, Si, B) Alloy. Intermetallics. 7, 1081-1087.

Zhang, W.J., Chen, G.L., Appel, F., Nieh, T.G \& Deevi S.C. (2001). A Preliminary Study on the Creep Behavior of Ti-45Al-10Nb Alloy. Materials Science and Engineering Part A, A315, 250-253.
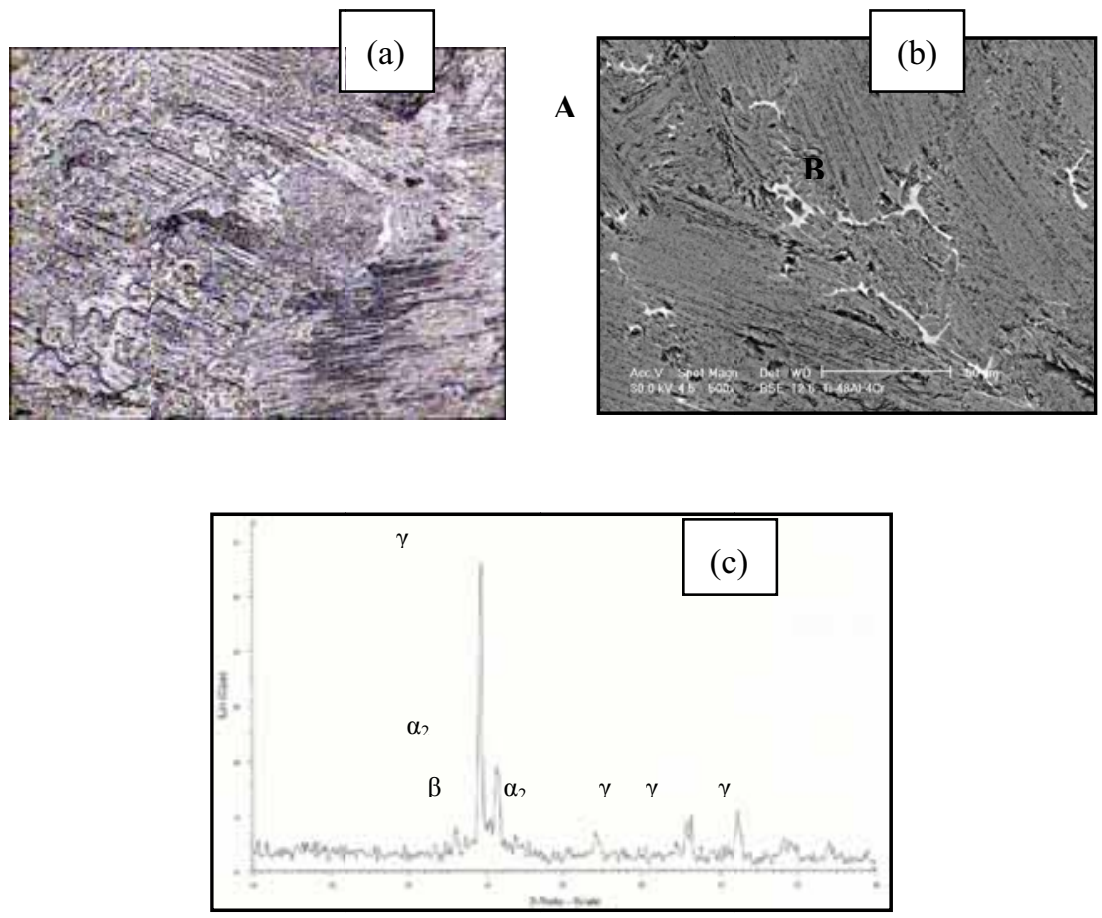

Figure 1. (a) Optical microstructure (200x), (b) SEM-BSE microstructure (500x) and (c) XRD result of as-cast Ti-48Al-4Cr.
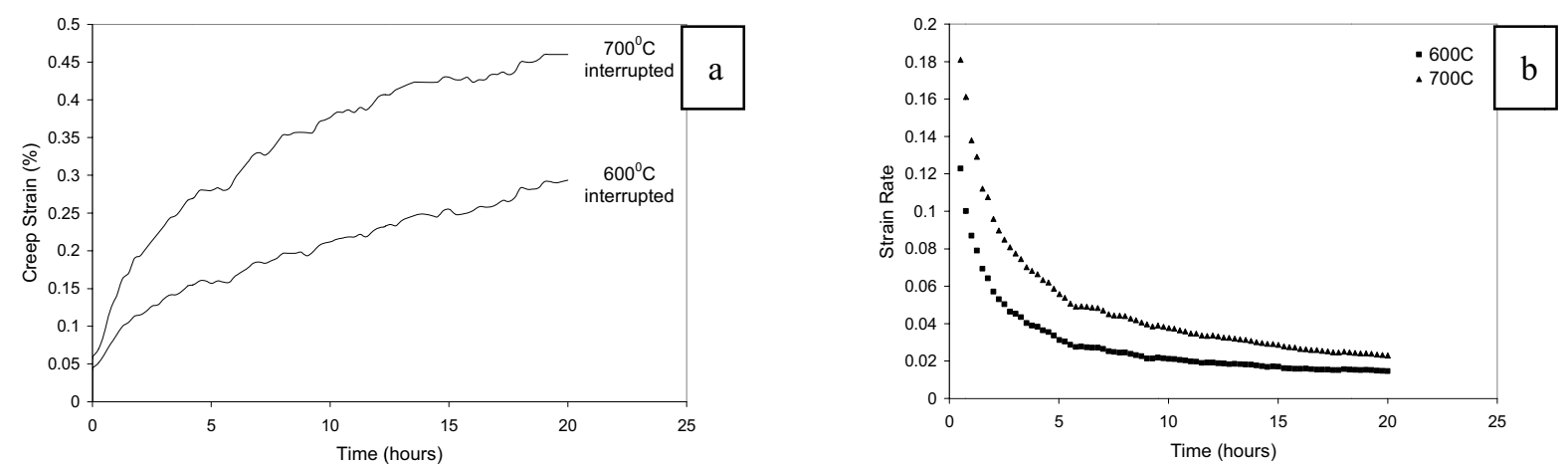

Figure 2. Creep curves of Ti-48Al-4Cr at temperatures ranging between $600-700^{\circ} \mathrm{C}$ and identical initial stress of $180 \mathrm{MPa}$ (a) creep strain (\%) vs time (hours) and (b) strain rate $\left(\mathrm{hr}^{-1}\right)$ vs time (hours) 

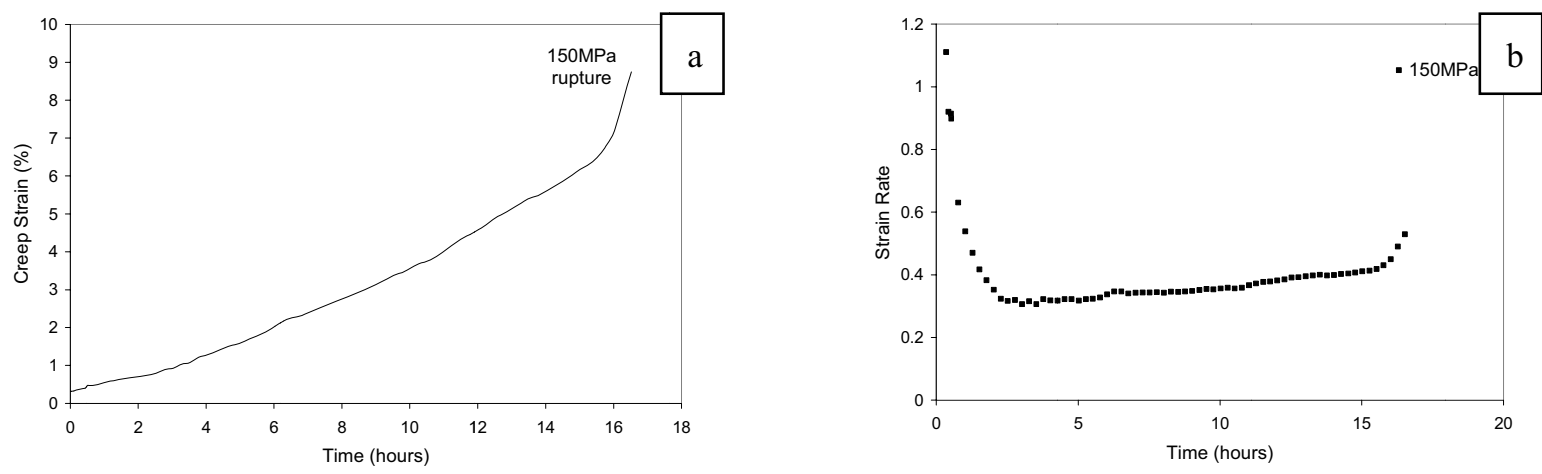

Figure 3. Creep curves of Ti-48Al-4Cr at $800^{\circ} \mathrm{C}$ and initial stress of $150 \mathrm{MPa}$

(a) creep strain (\%) vs time (hours) and (b) strain rate $\left(\mathrm{hr}^{-1}\right)$ vs time (hours)
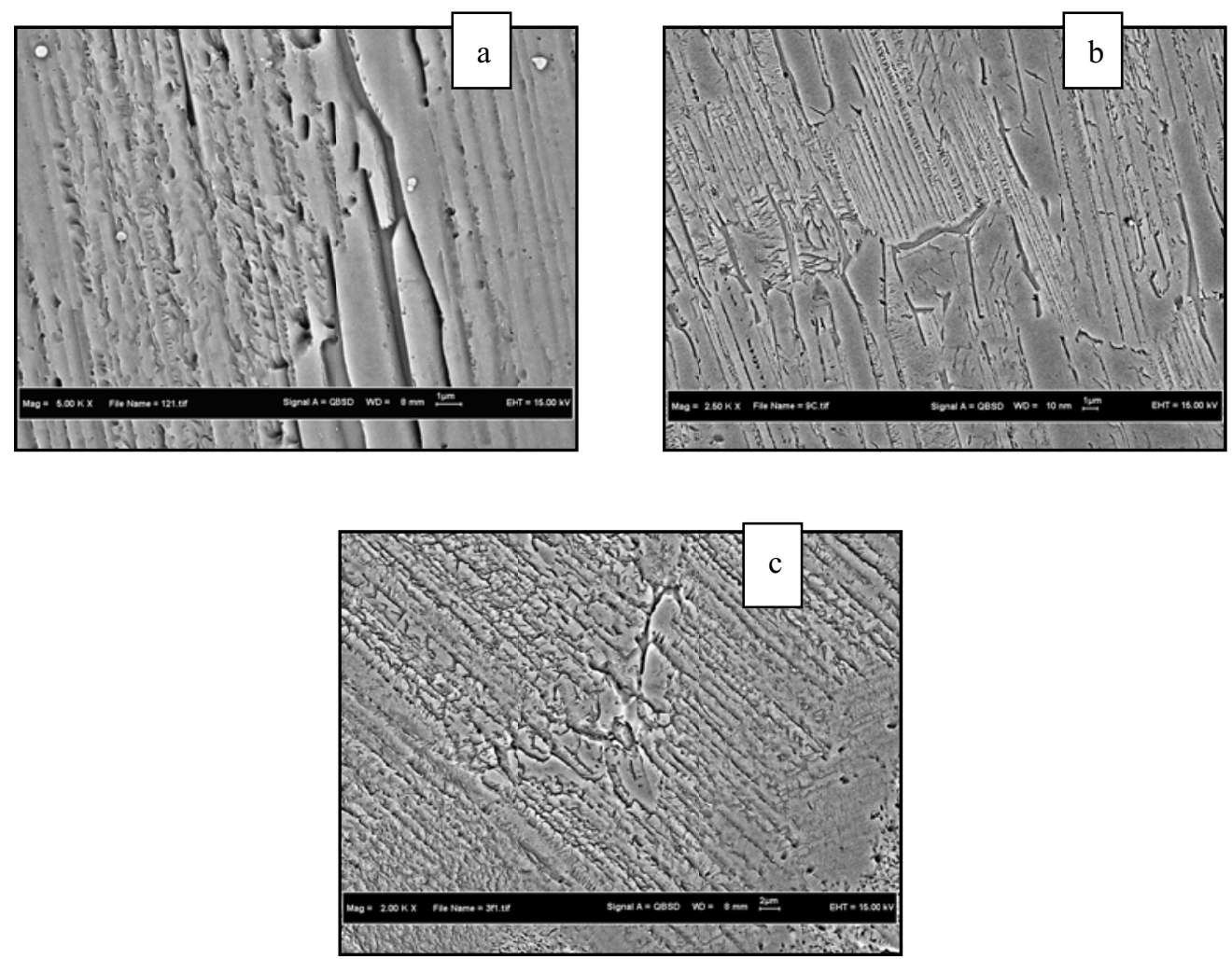

Figure 4. SEM-BSE micrograph showing microstructure of as-cast Ti-48Al-4Cr (a) after 20hours of creep deformation at $600^{\circ} \mathrm{C}$ and initial stress of $180 \mathrm{MPa}\left(5000 \mathrm{x}\right.$ ), (b) after 20 hours of creep deformation at $700^{\circ} \mathrm{C}$ and initial stress of $180 \mathrm{MPa}(2500 \mathrm{x})$ and (c) at near rupture surface after creep-rupture test at $800^{\circ} \mathrm{C}$ and initial stress of $150 \mathrm{MPa}(2000 \mathrm{x})$.

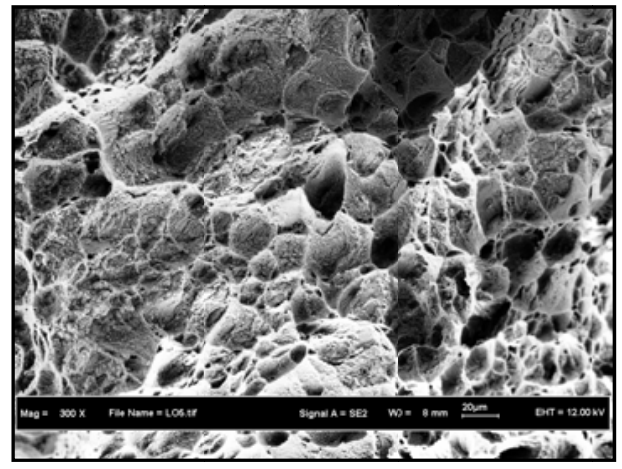

Figure 5. Fracture surface of as-cast Ti-48Al-4Cr after creep at $800^{\circ} \mathrm{C}$ and initial stress of $150 \mathrm{MPa}(300 \mathrm{x})$ 